\title{
Study of the Liquid Fraction and Thermophysical Properties of Semi-Solid Steels and Application to the Simulation of Inductive Heating for Thixoforming
}

\author{
J. Lecomte-Beckers ${ }^{1}$, A. Rassili ${ }^{2}$, M. Carton ${ }^{1}$, M. Robelet ${ }^{3}$ and R. Koeune ${ }^{1}$ \\ 1 MMS (IMGC, Bât. B52), University of Liège, Sart Tilman, 4000 Liège, Belgium, \\ \{jacqueline.lecomte, marc.carton, r.koeune\}@ulg.ac.be \\ 2 Institut Montefiore, University of Liège, Sart Tilman, 4000 Liège, Belgium, \\ A.Rassili@ulg.ac.be \\ 3 ASCOMETAL CREAS, BP 750042, 57301 Hagondange Cedex, France, \\ m.robelet@ascometal.lucchini.com
}

Summary. The thixoforming of steels is so complex that it requires more investigations regarding both the materials and the technical tools dedicated to the elaboration of the process. In this paper we will show the experimental determination of appropriate solidus-liquidus interval on eight different steel compositions. This critical parameter was obtained using Differential Scanning Calorimetry. The paper also presents the results of thermophysical property determination. These parameters are important for the inductive heating phase of a semi-solid forming (SSF) process. Thanks to the simulations of the inductive heating process, the other main results consist on the developments of the heating techniques that are suitable for the achieving of the sine qua none condition to the semi-solid process, which is the uniform temperature distribution in the reheated billet.

Key words: steel, thixoforming, thermophysical properties, liquid fraction, simulation.

\section{Introduction}

Thixoforming - or semi-solid processing - is the shaping of metal components in the semi-solid state. Major challenges for semi-solid processing include broadening the range of alloys that can be successfully thixoformed and developing alloys specifically for thixoforming. For this to be possible, the alloy must have an appreciable melting range and before forming, the microstructure must consist of solid metal spheroids in a liquid matrix. Characterisation of thermophysical properties of semi-solid steels for thixoforming is useful in two 
ways. First, to study and optimise the behaviour of alloys to be thixoformed, and secondly to obtain parameters to be incorporated in numerical models.

A sufficiently expanded solidus-liquidus interval is required which allows the formation of the desired microstructure under variation of temperature and holding time. As suggested by Meuser and Bleck (2002), the most preferable structure is a globulitic solid phase in a liquid matrix with decreasing viscosity during forming. Aluminium and magnesium alloys are the focus of numerous investigations, but research activities concerning the thixoformability of steel alloys are still in their very beginning. As suggested by Atkinson et al. (2000), for thixoforming the critical parameters must be as follows:

- Appropriate solidus-liquidus interval: Pure material and eutectic alloy are not thixoformable for want of a solidification interval. In general, the wider the solidification interval, the wider the processing window for thixoforming. For multicomponent systems thermodynamic software is available which allows the calculation of the maximum interval, provided basic data is available.

- Fraction solid versus temperature: The liquid fraction sensitivity, $\left(\mathrm{df}_{\mathrm{L}} / \mathrm{dT}\right)$, defined as the rate of change of the liquid fraction $\left(f_{L}\right)$ with temperature, is a very important parameter for semi-solid forming; it can be obtained experimentally by differential scanning calorimetry (DSC) and predicted by thermodynamic modelling. This would allow some systematic identification of suitable alloying systems.

Kazakov (2000) has recently summarised the critical parameters on the DSC curve and the associated fraction liquid versus temperature curve. The critical parameters as suggested by Kazakov are:

- The temperature at which the slurry contains $50 \%$ liquid: $\mathrm{T}_{1}$.

- The slope of the curve at fraction liquid $\mathrm{f}_{\mathrm{L}}=50 \%: \mathrm{dF} / \mathrm{dT}\left(\mathrm{T}_{1}\right)$. To minimize reheating sensitivity this slope should be as flat as possible.

- The temperature of the beginning of melting $\left(\mathrm{T}_{0}\right)$. The difference $\left(\mathrm{T}_{1}-\mathrm{T}_{0}\right)$ determines the kinetics of dendrite spheroidization during reheating.

- The slope of the curve in the region where the solidification process is complete: $\mathrm{dF} / \mathrm{dT}\left(\mathrm{T}_{\mathrm{f}}\right)$, where $\mathrm{T}_{\mathrm{f}}$ is the temperature of end of melting. In Kazakov's view this should be relatively flat to avoid hot shortness problems.

These parameters will be studied on some ferrous alloys in the first part of the paper. The second part deals with thermophysical properties.

Simulation techniques show great potential to acquire a good understanding of the Semi-Solid Metal (SSM) forming process. These simulations are intended, on one hand, to determine the optimal electrical and geometrical parameters for the inductive heating phase of a SSF process and on the other hand, to obtain an estimation of the forging loads for the thixoforging of an industrial part, e.g. a SKL-flange. The basis of the simulation of the inductive heating process is the solving of the Maxwell's equations, together with the equation of heat transfer (4). In the third part of the paper, various numerical and experimental results are compared. In particular, a typical time evolution 
of the temperature in the steel part, which is the key parameter in the SSM process, is shown. The basis of the modelling of the forming process is the solving of the deformation equations, taking into account thermal and rate dependence effects. Some important proportionality parameters needed are electrical resistivity, calorific capacity and thermal conductivity.

\section{Experimental Procedures}

We studied different alloys named C38 Asco Modif 1, C38 Asco modif 2, 100 Cr6 Asco modif 1, 50 Mn6 Asco modif 1, 45 Mn5 Asco modif 1 that were modified for thixoforming properties. As pointed out above, the main critical parameters for thixoforming must be as follow: appropriate solidusliquidus interval and fraction solid versus temperature. These two parameters are obtained from Differential Scanning Calorimetry (DSC). Secondly the thermophysical properties of the alloys have to be determined.

\subsection{Solidus-Liquidus Interval and Fraction Solid Versus Temperature Characterisation}

The applicability of a material for processing in the semi-solid state is defined by the solidus-liquidus interval and the development of liquid phase in the interesting temperature range. For the evaluation of the solidus and liquidus temperature a Differential Scanning Calorimetry (DSC) was used. The development of the liquid phase with increasing temperature was calculated using the values from the DSC-measurements. The evaluation of the liquid phase distribution is carried out by the application of a peak partial area integration. The whole area under the enthalpy-area curve is used to determine the melting enthalpy of the material. During DSC measurement, the typical melting peak obtained is shown in Fig. 1

The peak characteristics are:

- The changes of slope, jumps and peaks showing the thermal events (phase transformations, chemical reactions, etc.)

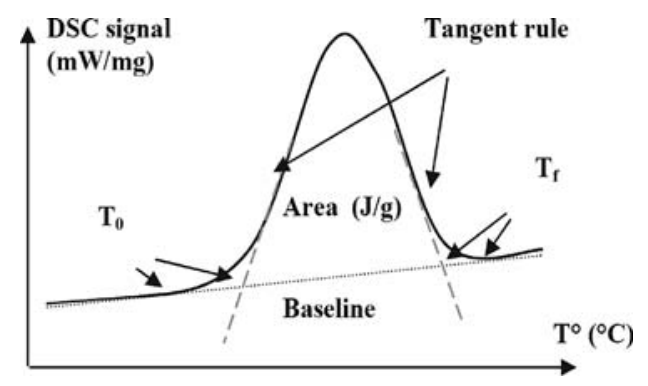

Fig. 1. Melting peak features 
- The peak area is the enthalpy variation of the transformation

- The specific heat is calculated from the baseline

- Solidus-liquidus interval: $\mathrm{T}$ end of melting-T beginning of melting $\left(T_{f}-T_{0}\right)$

We assume that the liquid fraction is proportional to the absorbed energy during the transformation. The sample is heated until total melting. Therefore, the liquid fraction can be calculated considering the peak area of the transformation, as shown in Fig. 2.

The characterisation of the melting peak is realised with the following parameters:

- Total area $=100 \%$ of the liquid fraction

- Beginning and end of melting

The liquid fraction at $T_{i}$ is determined with the following relation (1):

$$
\% \text { liquid }=\frac{\operatorname{Area}\left(T_{0}-T_{i}\right)}{\text { TotalArea }}
$$

\subsection{Thermophysical Properties Characterization}

\section{Dilatometry}

Dilatometry is a technique used to measure the relative dilatation $\Delta L / L_{0}$ of a material submitted to a temperature program $(\Delta L$ is the difference between the length at temperature $T$ and the initial length $L_{0}$ at room temperature). In our case, the sample holder for powder and pasty sample is required because we carried out the dilatation run tests for high temperatures, where the sample is in liquid state (Fig. 3).

\section{Average Expansion Coefficient}

From the dilatation values obtained and thanks to the relation (2), it was possible to calculate the average expansion coefficient $C T E\left(T_{1}-T_{2}\right)$ for the temperature interval $\left(T_{2}-T_{1}\right)$.

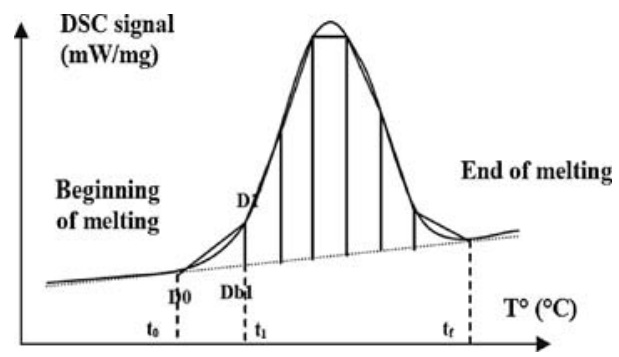

Fig. 2. Determination of the liquid fraction 


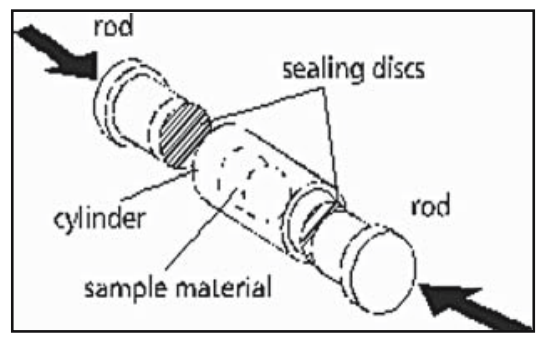

Fig. 3. Sample holder for powdery and pasty samples

$$
\operatorname{CTE}\left(T_{1}-T_{2}\right)=\frac{\frac{\Delta L}{L_{0}}\left(T_{2}\right)-\frac{\Delta L}{L_{0}}\left(T_{1}\right)}{T_{2}-T_{1}}
$$

where $T_{2}$ is the upper temperature limit, $T_{1}$ is the lower temperature limit and $\Delta L / L_{0}$ is the length change relative to $L_{0}$.

\section{Density}

Density $\rho(T)$ was calculated from the expansion values according to the following relation $(3)$.

$$
\rho(T)=\rho_{0}\left[1+3\left(\frac{\Delta L(T)}{L_{0}}\right)+3\left(\frac{\Delta L(T)}{L_{0}}\right)^{2}+\left(\frac{\Delta L(T)}{L_{0}}\right)^{3}\right]
$$

where $\rho_{0}$ is the density at reference (mostly ambient) temperature, $\Delta L(T)$ is the expansion of the specimen under investigation and $L_{0}$ is the specimen length at room temperature.

\section{DSC-Cp Determination}

DSC is a technique in which the difference in energy input into a substance and a reference material is measured as a function of temperature, while the substance and reference material are subjected to a controlled temperature program. Individual $C_{p}$ values at different temperatures are determined using a sapphire as a standard according to the following (4).

$$
C_{p}=\frac{m_{\text {Standard }}}{m_{\text {Sample }}} \frac{D S C_{\text {Sample }}-D S C_{\text {Bas }}}{D S C_{\text {Standard }}-D S C_{\text {Bas }}} C_{p, \text { Standard }}
$$

where $C_{p}$ is the specific heat of the sample at temperature $T, C_{p, \text { Standard }}$ is the tabulated specific heat of the standard at temperature $T, m_{\text {Standard }}$ is the mass of the standard, $M_{\text {Sample }}$ is the mass of the sample, DSC Sample is the value of DSC signal at temperature $T$ from the sample curve, $D S C_{\text {Standard }}$ is the value of DSC signal at temperature $T$ from the standard curve and $D S C_{B a s}$ is the value of DSC signal at temperature $T$ from the baseline. 


\section{Thermal Diffusivity - Laser Flash}

The front face of a cylindrically shaped piece is homogeneously heated by an unfocused laser pulse (Fig. (4). On the rear face of the test piece the temperature increase is measured as a function of time. The mathematical analysis of this temperature/time function allows the determination of the thermal diffusivity $D(T)$ as presented in (Cape and Lehman, 1963) and illustrated in

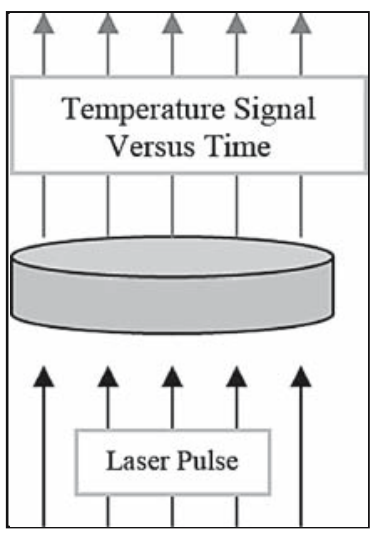

Fig. 4. Laser pulse on the sample

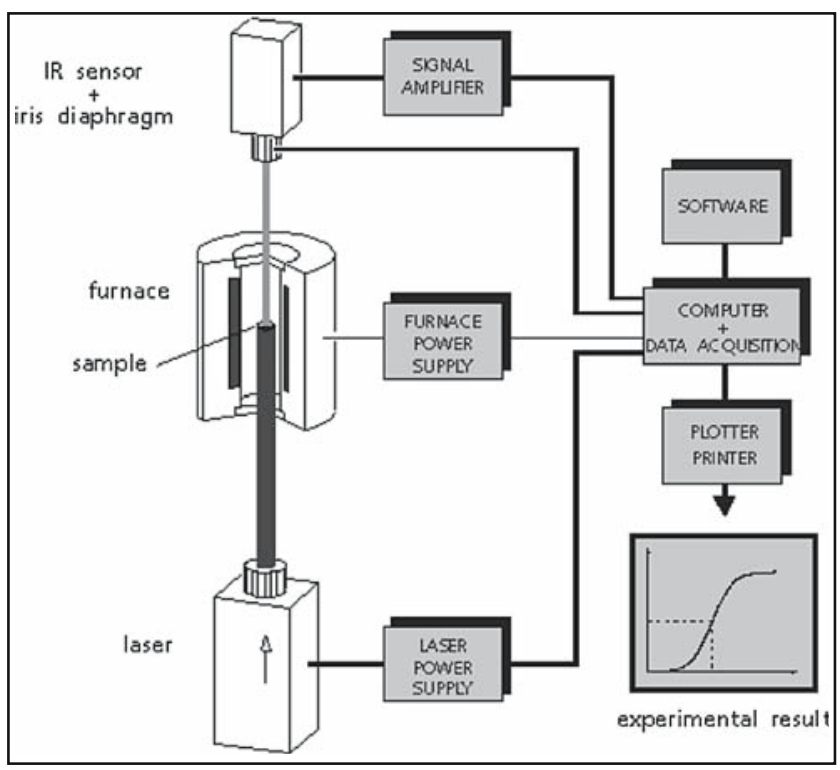

Fig. 5. Laser flash apparatus schematic 
Fig. 5. As we determined diffusivity up until the liquid state, we used a special quartz sample container.

\section{Thermal Conductivity}

Knowledge of thermal diffusivity $D(T)$, density $\rho(T)$ and specific heat $C_{p}(T)$ allowed the determination of the thermal conductivity $\chi(T)$, calculated according to the Laplace relation (5):

$$
\chi(T)=D(T) \rho(T) C_{p}(T)
$$

\section{Results}

\subsection{Solidus-Liquidus Interval and Fraction Solid Versus Temperature Characterization}

Some basic alloys are studied and compared to modified alloys. The basic alloys are $\mathrm{C} 34$, $\mathrm{C} 80^{1}$ and $100 \mathrm{Cr} 6{ }^{1}$. The modified alloys are $\mathrm{C} 38$ Asco modif $1^{1}$ and C38 Asco modif $2^{1}, 100 \mathrm{Cr} 6$ Asco modif $1^{1}, 45 \mathrm{Mn} 5$ Asco modif $1^{1}$ and $50 \mathrm{Mn} 6$ Asco modif $1^{1}$. All properties are compared to the base alloy C38. The base alloy C38 was used to study the effect of heating rate on DSC curves. The $50 \mathrm{Mn} 6$ Asco modif 1 alloy was used to study the homogeneity of the billet. The results are presented hereafter. Figures 6, 8, 10, 12, 14, 16, 18, 20, 22 24, 26, 28 and 30 show the DSC signal of the melting peak and Fig. 7 , 9 11, 13, 15, 17, 19, 21, 23, 25, 27, 29 and 31 the corresponding liquid fraction.

\section{C38}

The DSC signal and the liquid fraction of C38 are shown in Figs. 6 and 7 Different heating rates were used $\left(2^{\circ} / \mathrm{min}, 10^{\circ} / \mathrm{min}\right.$ and $\left.20^{\circ} / \mathrm{min}\right)$. The DSC curves show that the DSC signals increase with heating rate but the sensitivity and the peak separation decrease. This fact will probably affect the fast inductive heating, but DSC is limited to $20^{\circ} / \mathrm{min}$ which approaches best the industrial heating rates. All subsequent experiments were therefore conducted with a heating rate of $20^{\circ} / \mathrm{min}$. The interest of the heating at $2^{\circ} \mathrm{C} / \mathrm{min}$ is that it shows the intermediate kink in the liquid fraction versus temperature curve.

During melting of C38 we observed three different peaks, which are related to the transformation:

- $\gamma \rightarrow \gamma+$ liquid,

- peritectic transformation $\gamma+$ liquid $\rightarrow \delta+$ liquid, and

$-\delta+$ liquid $\rightarrow$ liquid

\footnotetext{
${ }^{1}$ The composition follows euronorm DIN code. C38 = (carbon 0.38\%), C80 = (carbon $0.80 \%), 100 \mathrm{Cr} 6=($ carbon $1 \%$, Cr $1.5 \%), 50 \mathrm{Mn} 6=($ carbon $0.5 \%$, Mn $1.5 \%), 45 \operatorname{Mn} 5=($ carbon $0.45 \%$, Mn $1 \%)$.
} 


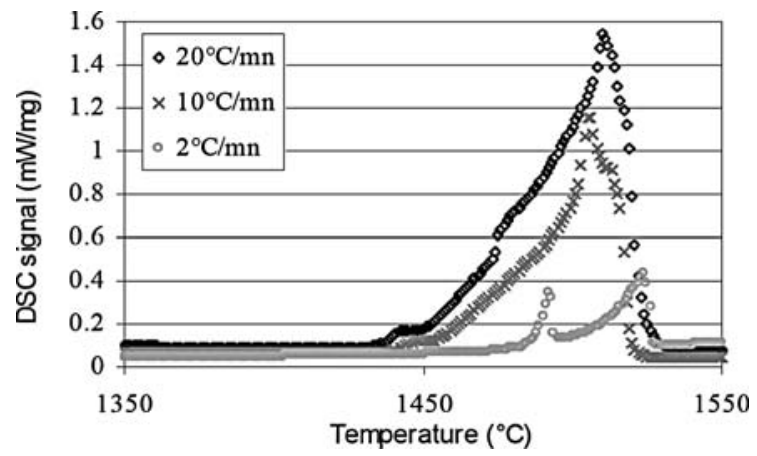

Fig. 6. DSC signal of C38

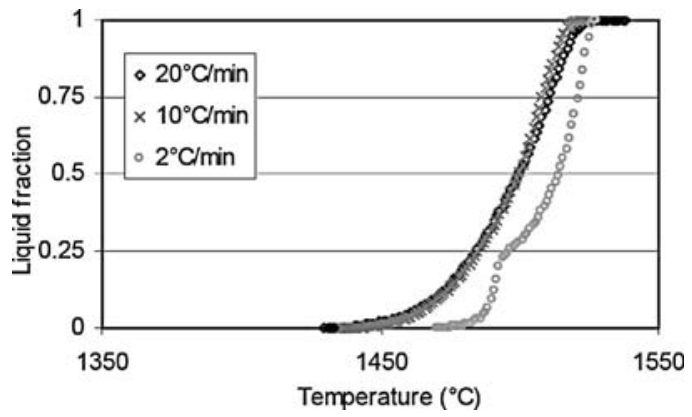

Fig. 7. Liquid fraction of C38

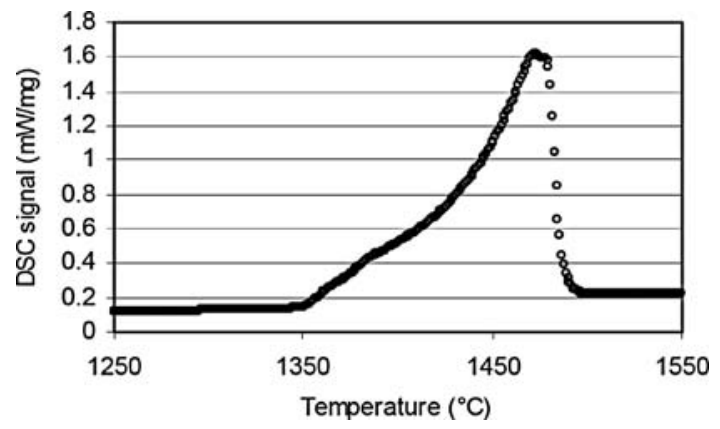

Fig. 8. DSC signal of C80 


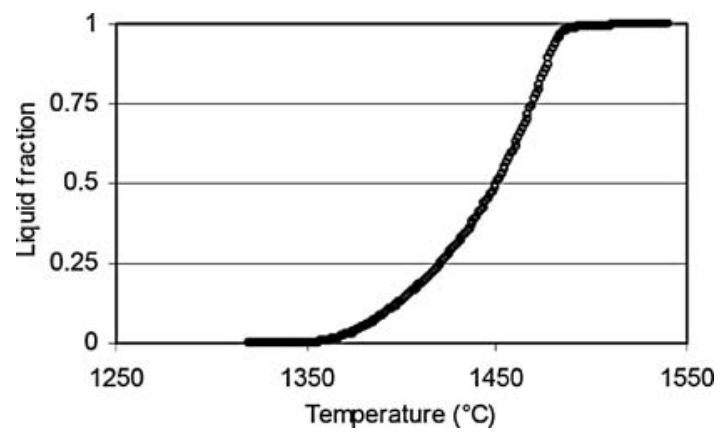

Fig. 9. Liquid fraction of $\mathrm{C} 80$

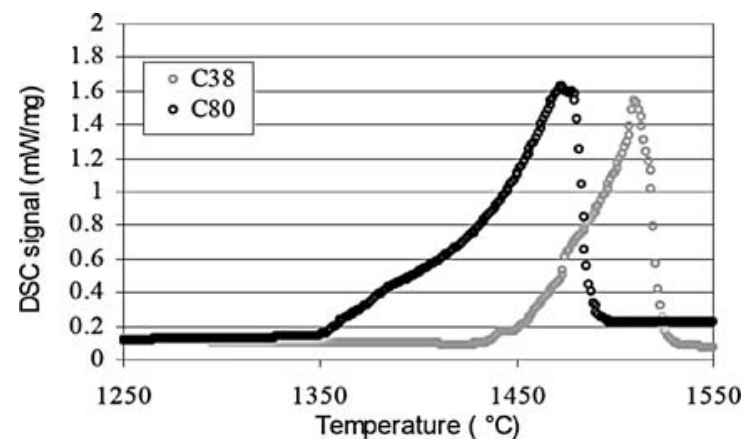

Fig. 10. Comparison of the DSC signal between C38 and C80

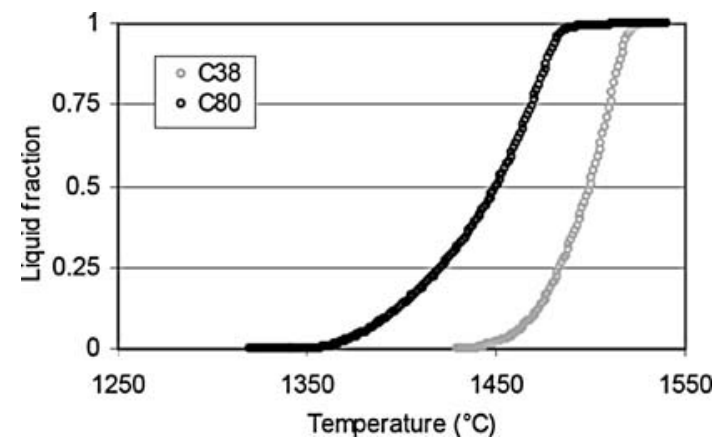

Fig. 11. Comparison of the liquid fraction between C38 and C80 


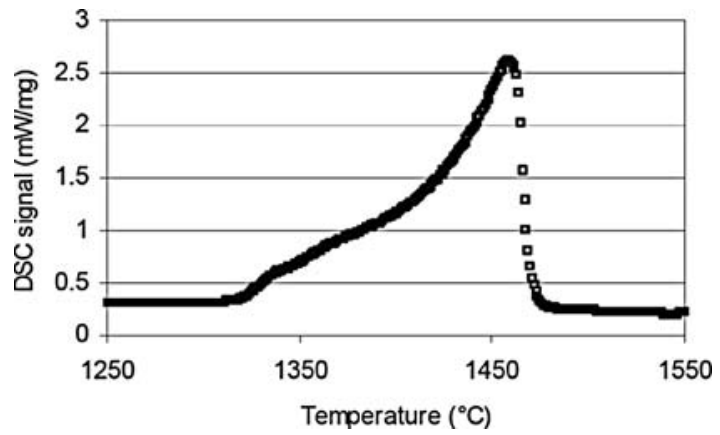

Fig. 12. DSC signal of $100 \mathrm{Cr} 6$

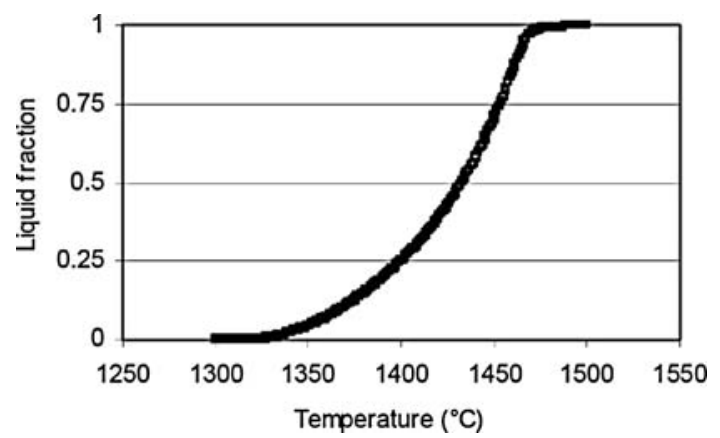

Fig. 13. Liquid fraction of $100 \mathrm{Cr} 6$

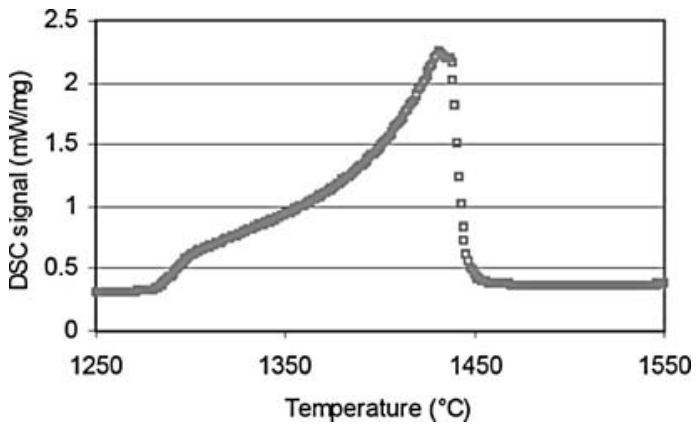

Fig. 14. DSC signal of 100 Cr6 Asco modif 1 


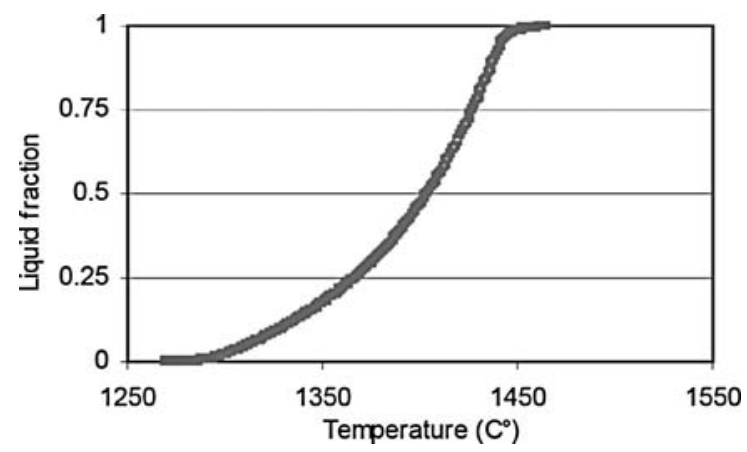

Fig. 15. Liquid fraction of 100 Cr6 Asco modif 1

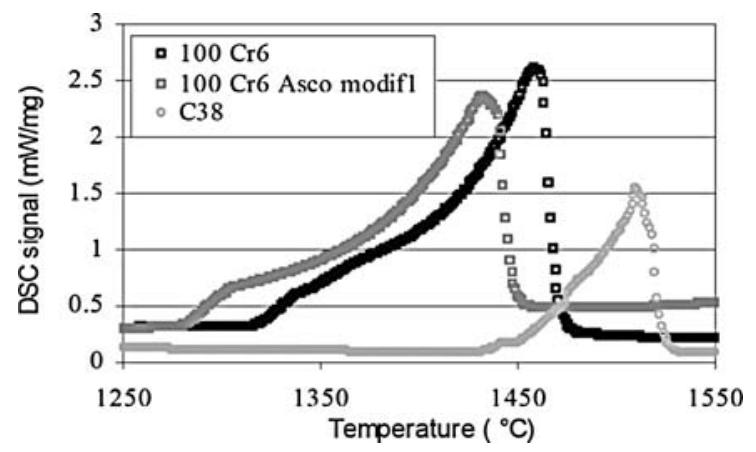

Fig. 16. Comparison of the DSC signal between C38, 100 Cr6 and 100Cr6 Asco modif 1

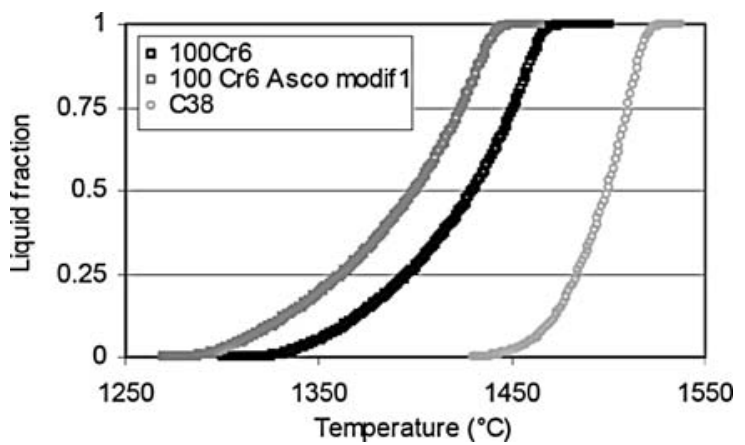

Fig. 17. Comparison of the liquid fraction between C38, $100 \mathrm{Cr} 6$ and 100Cr6 Asco modif 1 


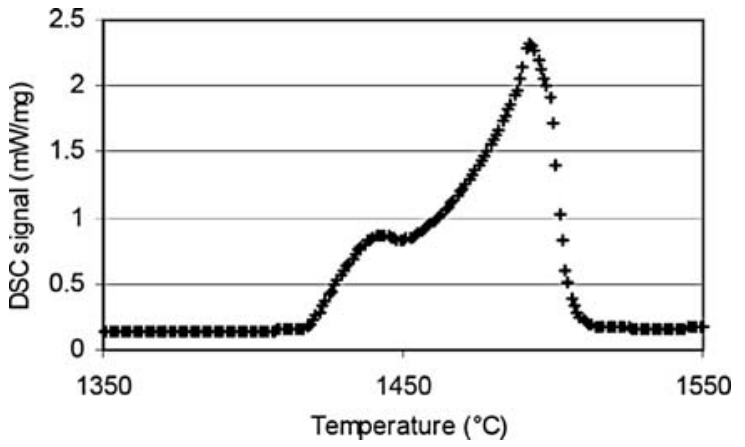

Fig. 18. DSC signal of C38 Asco modif 1

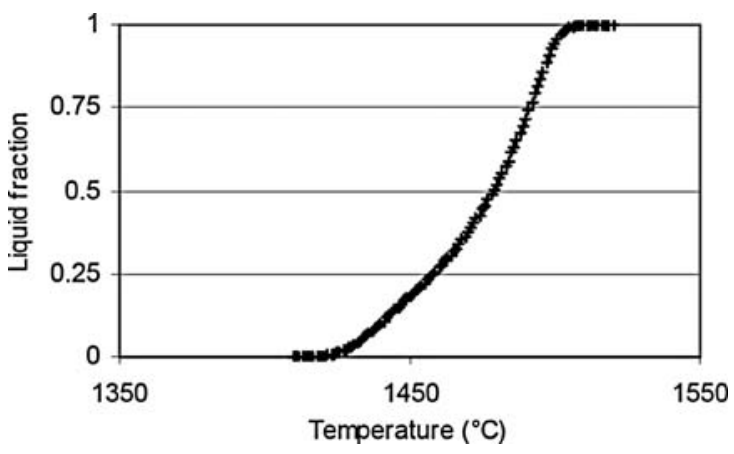

Fig. 19. Liquid fraction of C38 Asco modif 1

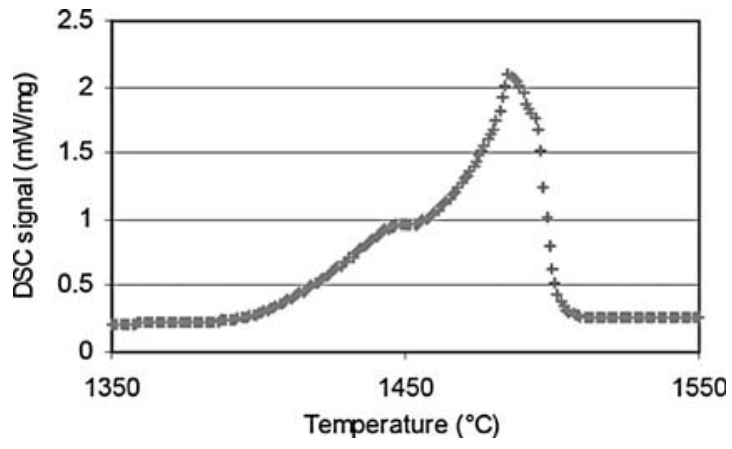

Fig. 20. DSC signal of C38 Asco modif 2 


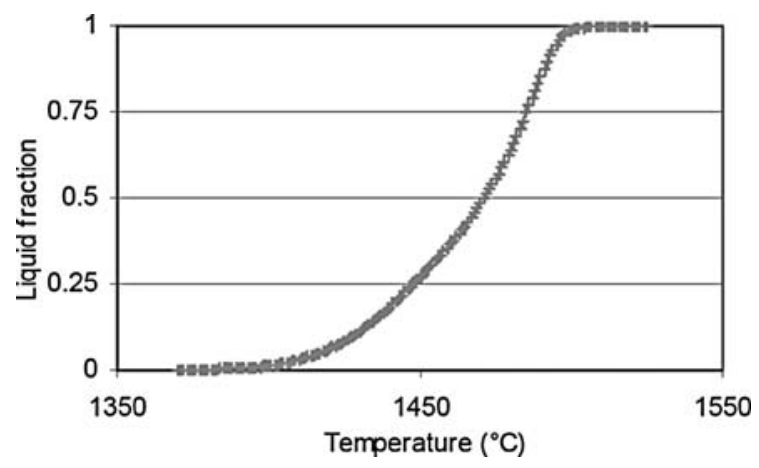

Fig. 21. Liquid fraction of C38 Asco modif 2

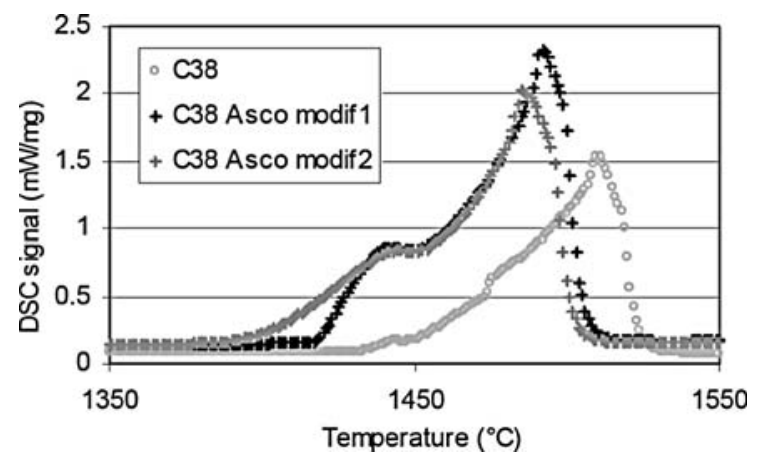

Fig. 22. Comparison of the DSC signal between C38, C38 Asco modif 1 and C38 Asco modif 2

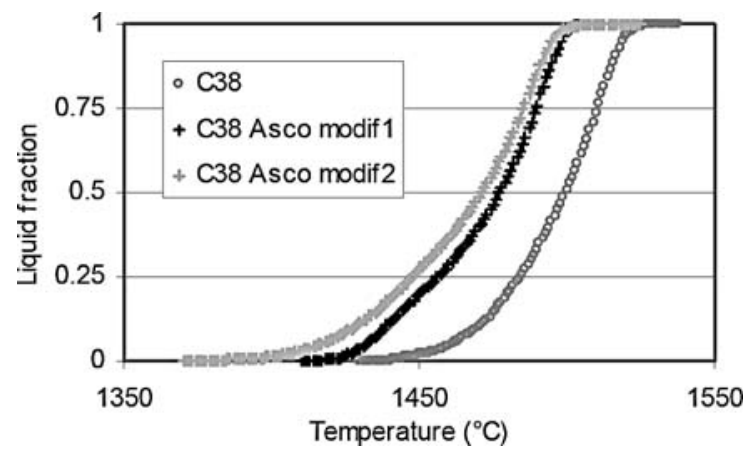

Fig. 23. Comparison of the liquid fraction between C38, C38 Asco modif 1 and C38 Asco modif 2 


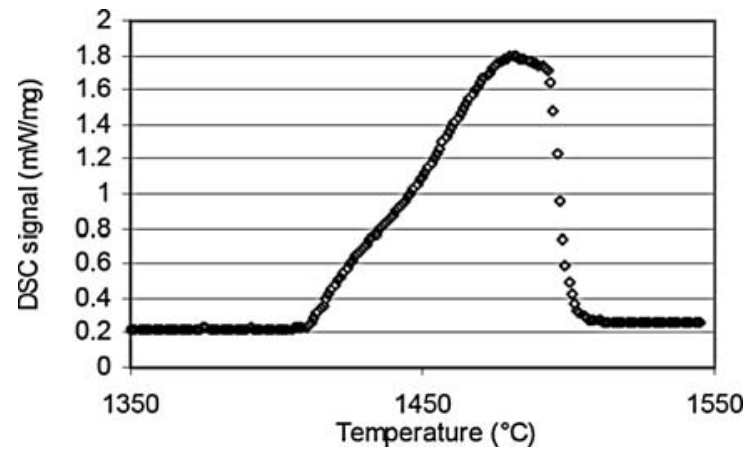

Fig. 24. DSC signal of 45Mn5 Asco modif 1

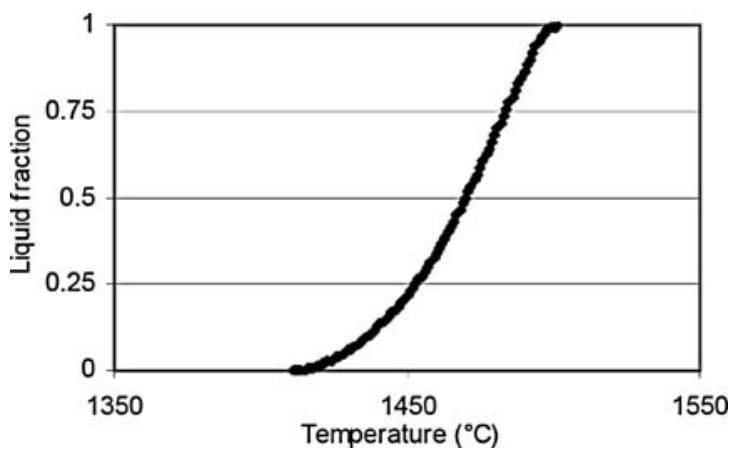

Fig. 25. Liquid fraction of $45 \mathrm{Mn} 5$ Asco modif 1

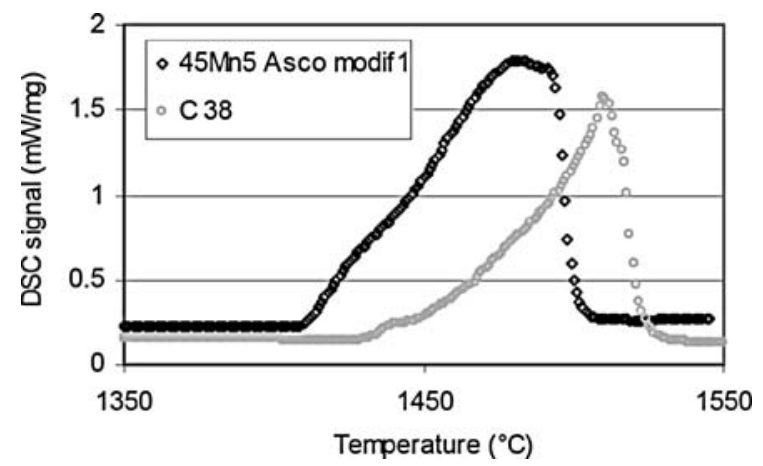

Fig. 26. Comparison of the DSC signal between C38 and 45Mn5 Asco modif 1 


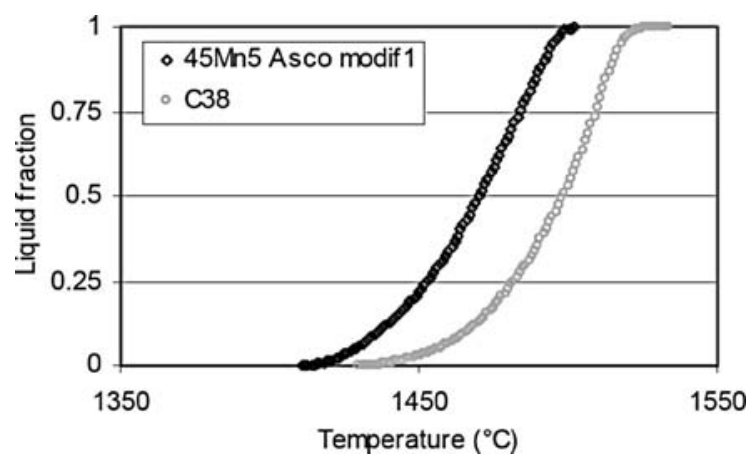

Fig. 27. Comparison of the liquid fraction between C38 and 45Mn5 Asco modif 1

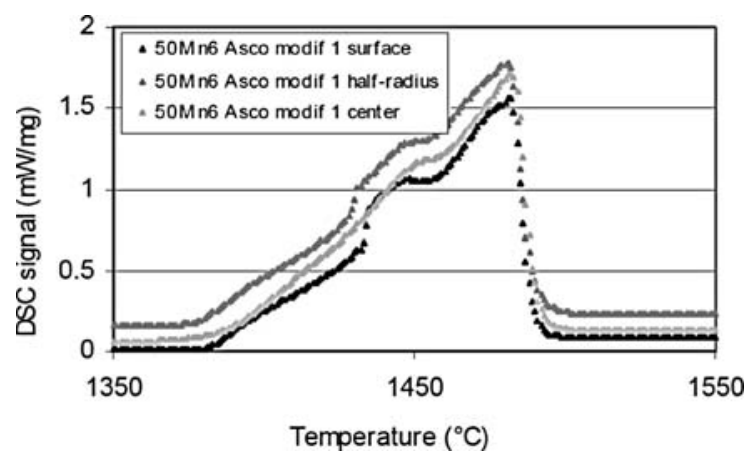

Fig. 28. DSC signal of 50 Mn6 Asco modif 1

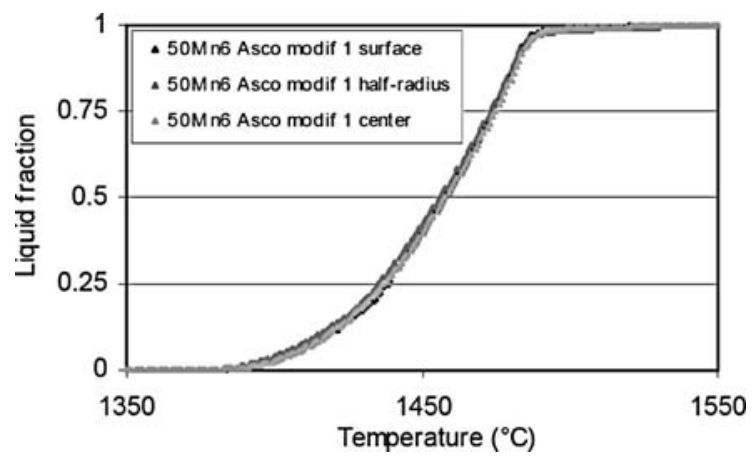

Fig. 29. Liquid fraction of $50 \mathrm{Mn} 6$ Asco modif 1 


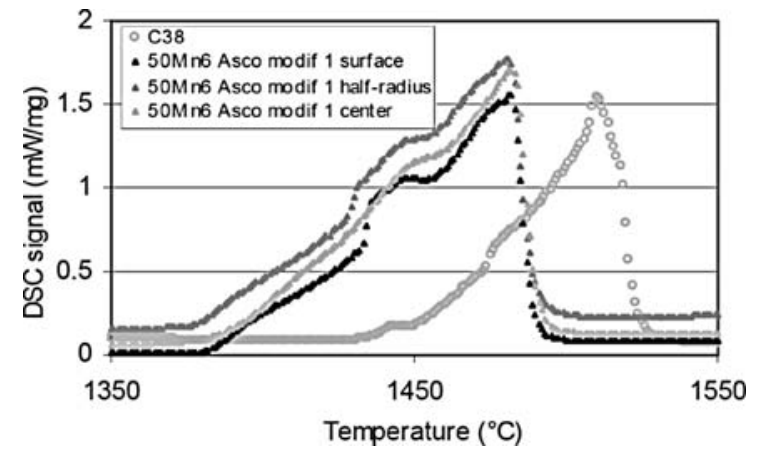

Fig. 30. Comparison of the DSC signal between C38 and 50 Mn6 Asco modif 1

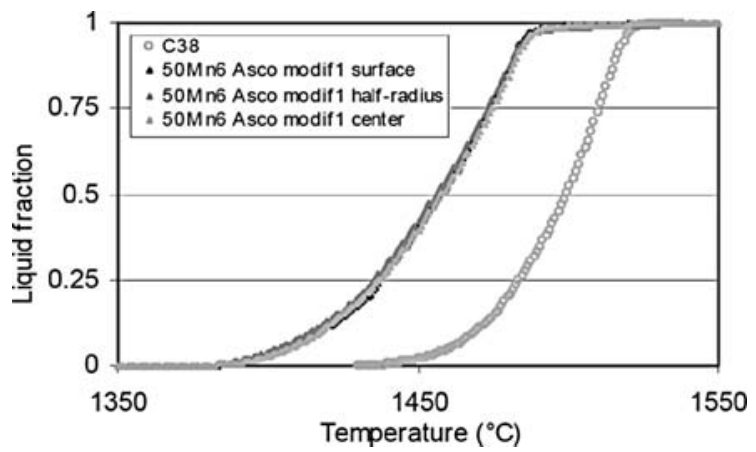

Fig. 31. Comparison of the liquid fraction between C38 and 50 Mn6 Asco modif 1

\section{C80, C38}

The DSC signal during melting and the liquid fraction of C80 are shown in Figs. 8 and 9 The comparison between C38 and C80 is shown in Figs. 10] and 11

With regard to Kazakov parameters, C80 exhibits better behaviour than C38. The beginning of melting $T_{0}$ is lower, $T_{1}$ is lower, the solidification interval $\left(T_{f}-T_{0}\right)$ is larger (see Table 1 ), and the slope of the curve $d F / d T$ is flatter at $T_{1}$ and $T_{f}$.

\section{Cr6, 100 Cr6 Asco modif 1, C38}

The DSC signal and the liquid fraction of $100 \mathrm{Cr} 6$ and $100 \mathrm{Cr} 6$ Asco modif 1 are shown in Figs. 12,13 and 14, 15 respectively. The C38, 100Cr6 and 100Cr6 Asco modif 1 results are shown in Figs. 16 and 17

With regard to Kazakov parameters, 100 Cr6 Asco modif 1 exhibits better behaviour than $100 \mathrm{Cr} 6$ and C38 one. The beginning of melting $T_{0}$ is lower, $T_{1}$ is lower, the solidification interval $\left(T_{f}-T_{0}\right)$ is slightly larger (see Table 1 ) and the slope of the curve $d F / d T$ is flatter at $T_{1}$. 
Table 1. Characteristic temperatures and slopes

\begin{tabular}{lllllll}
\hline alloys & $\begin{array}{l}T_{0} \\
\left({ }^{\circ} \mathrm{C}\right)\end{array}$ & $\begin{array}{l}T_{1} \\
\left({ }^{\circ} \mathrm{C}\right)\end{array}$ & $\begin{array}{l}T_{f} \\
\left({ }^{\circ} \mathrm{C}\right)\end{array}$ & $\begin{array}{l}T_{f}-T_{0} \\
\left({ }^{\circ} \mathrm{C}\right)\end{array}$ & $\begin{array}{l}\text { slope } \\
\text { at } T_{1}\end{array}$ & $\begin{array}{l}\text { slope } \\
\text { at } T_{f}\end{array}$ \\
\hline C38 & 1430 & 1500 & 1536 & 106 & 0.0200 & 0.0019 \\
C38 Asco modif 1 & 1415 & 1478 & 1517 & 102 & 0.0185 & 0.0017 \\
45 Mn5 Asco modif 1 & 1411 & 1470 & 1501 & 90 & 0.0173 & 0.0020 \\
50 Mn6 Asco modif 1 (surface) & 1389 & 1458 & 1519 & 130 & 0.0136 & 0.0002 \\
50 Mn6 Asco modif 1 (half-radius) & 1386 & 1456 & 1520 & 134 & 0.0127 & 0.0002 \\
50 Mn6 Asco modif 1 (center) & 1382 & 1456 & 1519 & 137 & 0.0139 & 0.0002 \\
C38 Asco modif 2 & 1379 & 1472 & 1520 & 141 & 0.0145 & 0.0007 \\
C80 & 1361 & 1450 & 1491 & 130 & 0.0114 & 0.0003 \\
100 Cr6 & 1315 & 1431 & 1487 & 172 & 0.0111 & 0.0004 \\
100 Cr6 Asco modif 1 & 1278 & 1402 & 1460 & 182 & 0.0097 & 0.0013 \\
\hline
\end{tabular}

\section{C38 Asco Modif 1, C38 Asco Modif 2, C38}

The DSC signal and the liquid fraction of C38 Asco modif 1 are shown in Figs. 18 and 19. The DSC signal and the liquid fraction of C38 Asco modif 1 are shown in Figs. 20 and 21 The C38, C38 Asco modif 1 and 2 results are shown in Figs. 22 and 23.

With regard to Kazakov parameters, C38 Asco modif 2 exhibits better behaviour than C38 Asco modif 1 and C38 ones. The beginning of melting $T_{0}$ is lower, $T_{1}$ is lower, the solidification interval $\left(T_{f}-T_{0}\right)$ is slightly larger (see Table 1) and the slope of the curve $d F / d T$ is flatter at $T_{1}$ and $T_{f}$.

\section{Mn5 Asco Modif 1 and C38}

The DSC signal during melting and the liquid fraction of C38 Asco modif 1 are shown in Figs. 24 and 25.

The comparison between C38 and 50Mn6 Asco modif 1 is shown in Figs. 26 and 27 The conclusions are similar to the other alloys, the behaviour of 45 Mn5 Asco modif 1 is better than C38.

\section{Mn6 Asco modif 1}

In order to determine the ingot homogeneity, three samples of 50Mn6 Asco modif 1 (named surface, half-radius and centre) were taken and studied. These results are as follows (Figs. 28 and 29). They show that the behaviour of the ingot is rather homogeneous regarding liquid fraction. This is of course important for industrial practice.

The comparison between C38 and 50Mn6 Asco modif 1 is shown in Figs. 30 and 31. As regarding Kazakov parameters, the behaviour of 50 Mn6 Asco modif 1 is better than C38 one. The beginning of melting $T_{0}$ is lower, $T_{1}$ is 
lower, the solidification interval $\left(T_{f}-T_{0}\right)$ is slightly larger (see Table 1) and the slope of the curve $d F / d T$ is flatter at $T_{1}$ and $T_{f}$.

\section{Alloys Features During Melting}

Table 1 gives main characteristic temperatures and slopes of the liquid fraction curve during melting at $20^{\circ} / \mathrm{min}$. Alloys are classified following decreasing $T_{0}$.

It is clear that for non alloyed steels the C38 Asco modif 2 gives the best results: $T_{0}$ and $T_{1}$ are lower, $\left(T_{f}-T_{0}\right)$ is larger, the slopes at $T_{1}$ and $T_{f}$ are lower than those of C38. It was used for the simulation of heating. Regarding low alloyed steels, $45 \mathrm{Mn} 5$ Asco modif 1 is not interesting. On the contrary 100 Cr6, 100 Cr6 Asco modif 1 and 50 Mn 6 Asco modif 1 show good behaviour.

\subsection{Thermophysical Properties Characterisation}

These properties were determined on the alloy C38 Asco Modif 2 and was used for the simulation of heating phase. The results of that simulation are shown in the next part of this study.

\section{Dilatometry and CTE}

The dilatation and CTE results are shown in Figs. 32 and 33 Table 2 gives values of the relative dilatation.

\section{Density}

The Fig. 34 shows the evolution of the density during heating in terms of temperature. The peak observed at $750^{\circ} \mathrm{C}$ is due to the phase transformation austenite-ferrite.

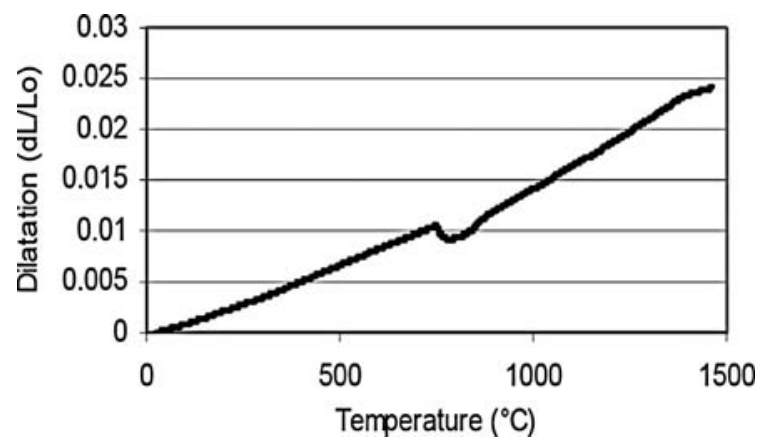

Fig. 32. Evolution of the dilatation during heating 


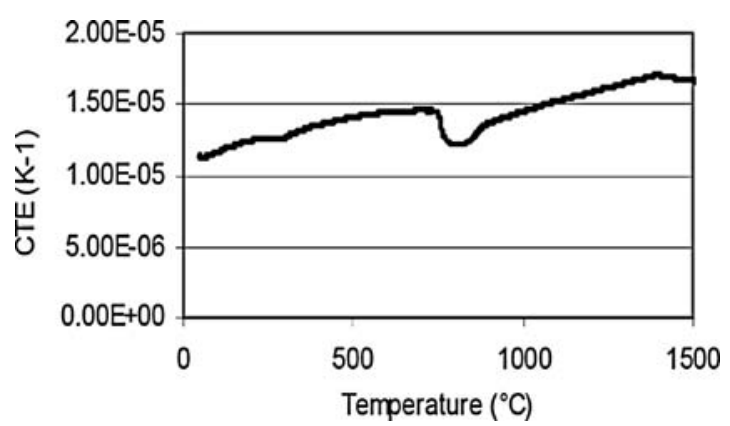

Fig. 33. Evolution of the CTE during heating

Table 2. Relative dilatation during heating

\begin{tabular}{ll}
\hline temperature $\left({ }^{\circ} \mathrm{C}\right)$ & relative dilatation $\left(\Delta L / L_{0}\right)$ \\
\hline 100 & $8.39 \mathrm{E}-04$ \\
500 & $6.65 \mathrm{E}-03$ \\
1000 & $1.41 \mathrm{E}-02$ \\
1500 & $2.45 \mathrm{E}-02$ \\
\hline
\end{tabular}

\section{DSC-Cp Determination}

The evolution of the specific heat versus temperature is shown in Fig. 35and 36

We can see a peak around $750^{\circ} \mathrm{C}$. This is the phase transformation (austenite-ferrite) already seen from the dilatometry. The dramatic increase about $1400^{\circ} \mathrm{C}$ is due to the sample melting. The specific heat is directly calculated from the DSC curves. Therefore if a transformation occurs during DSC measurement, it influences also $c_{p}$ measurement. Fig. 35 gives specific heat values if we take into account the quantity of heat $\Delta H$ released during the transformations, hence the y-axis title "apparent specific heat". Ignoring the quantity of heat $\Delta H$, we obtain the specific heat values shown in Fig. 36

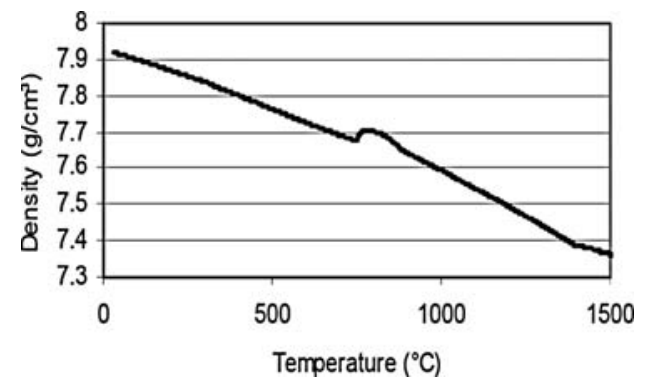

Fig. 34. Evolution of the density during heating 


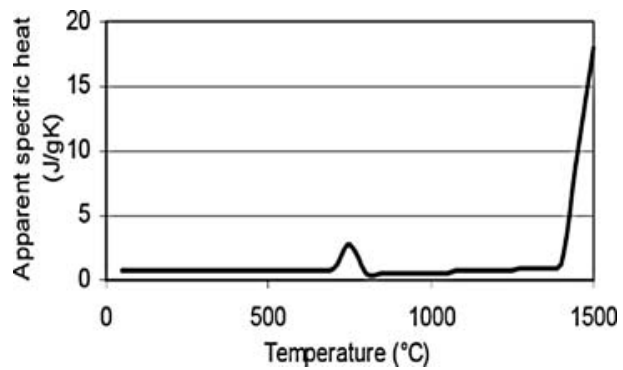

Fig. 35. Evolution of the apparent specific heat during heating

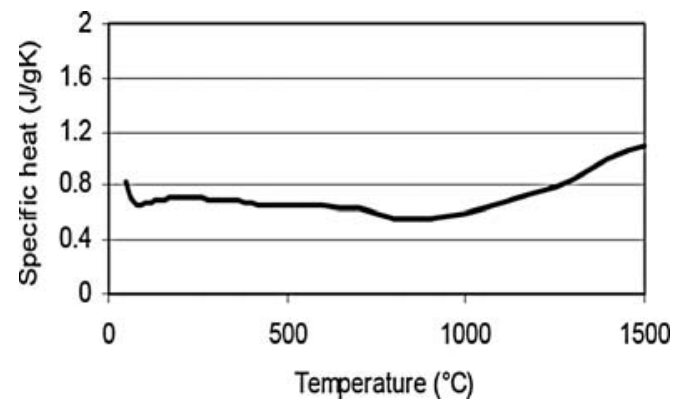

Fig. 36. Evolution of the specific heat during heating

\section{Thermal Diffusivity and Conductivity}

The behaviour of the diffusivity during heating is shown below, Fig. 37. The thermal conductivity is shown in Fig. 38

The behaviour of the thermal conductivity is similar to the thermal diffusivity. The values decrease until about $750^{\circ} \mathrm{C}$. When the phase transformation occurs, the thermal conductivity increases until the beginning of melting. Because of the phase change energy consumption, there is a dramatic diminution during melting, and the more liquid, the smaller the thermal conductivity.

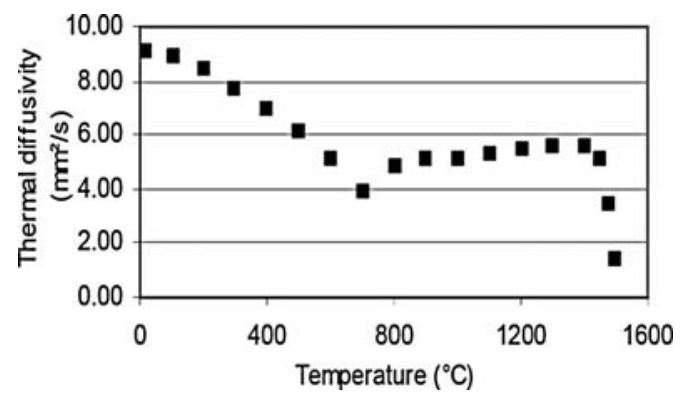

Fig. 37. Evolution of the thermal conductivity during heating 


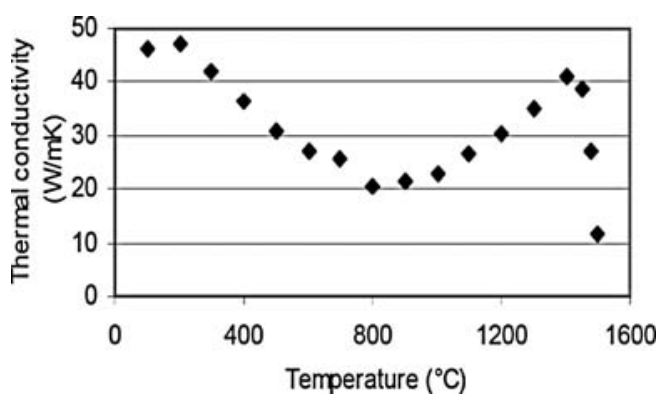

Fig. 38. Evolution of the thermal diffusivity during heating

\section{Inductive Heating Simulation}

Adequate heating cycles are necessary to maintain the globular structure and thus the thixotropic properties of the used steel. In this manner, the simulation of the inductive heating process is of a great help in order to establish the correct heating parameters and by the way to help controlling the heating process.

The numerical simulation of the inductive heating consists of the use of adequate softwarebased on the finite element method for field calculations. The software uses the formulations that consider the magneto-thermal coupling involved in the case of the inductive heating process. The software environment used to perform the simulations is called GetDP (Dular et al., 1998). Its main feature is the ability to write the models describing physical phenomena directly in input files (ASCII Format), in a form similar to their mathematical expression. This enables an efficient evaluation of the effects of changes in modelling decisions, from the straightforward definition of complex non-linear physical characteristics, to the definition of the various couplings, solving algorithms and post-processing operations.

The steel properties required as an input by the implemented numerical models are of two kinds. First, we need the thermal conductivity and the calorific capacity experimentally determined earlier in this work. Then, the magnetic permeability and the electrical conductivity shown in Fig. 39] are also necessary. All these properties are temperature dependent, which makes of course, the problem non-linear.

The mathematical details of the process were deeply explained in previous works [4]. We will show only some results obtained after the first simulations, such as the temperature and the liquid-fraction-distributions in the billet during the re-heating process. We can conclude from the geometrical optimisations that the ideal coil geometry is the parabolic one. For the reheating of small billets like for the SKL flange, a coil of six turns is enough.

The electrical parameters are the most important ones and require the use of the exact material properties; they include mainly the heating frequency, power, voltage and current. Figure 40 shows the optimised geometry as well 


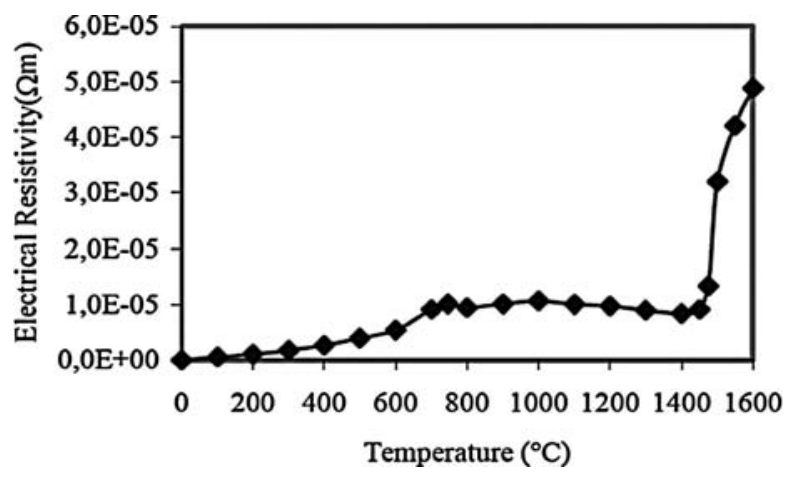

Fig. 39. Electrical resistivity

as the temperature colour map of the re-heated billet for the SKL Flange. The model shows a very good temperature distribution within the billet as shown in Fig. 41] The corresponding heating power is given by Fig. 42 ,

In parallel to the simulation of the electrical and geometrical parameters, to deal with a good and uniform temperature distribution, the simulation of the liquid fraction depending on the heating parameters was carried out. The uniform temperature distribution and the use of correct physical properties helped a lot on determining the liquid fraction distribution given by Fig. 43 where we see that with the above heating cycle we can reach $40 \%$ liquid fraction.

After setting up the model of the inductive heating simulations, several experiments were realized in order to validate the theoretical assumptions. In order to avoid more expenses for these validations, we decided to use an existing coil of 7 turns even known the coupling is weak. The aim of these experiments is to reproduce by simulations the experimental results and then to adjust the parameters of the model. Figure 44 shows the validation geometry and the temperature colour map in the billet.

In order to respect the amount of material used for the SKL Flange, we have reduced the dimensions of the billet. The simulated and measured parameters are in very good agreement if we take into account that for electrical resistivity, we used only a theoretical approach and this is due to the lack of

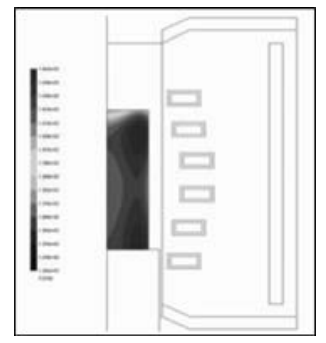

Fig. 40. Temperature colour map for the SKL Flange billet 


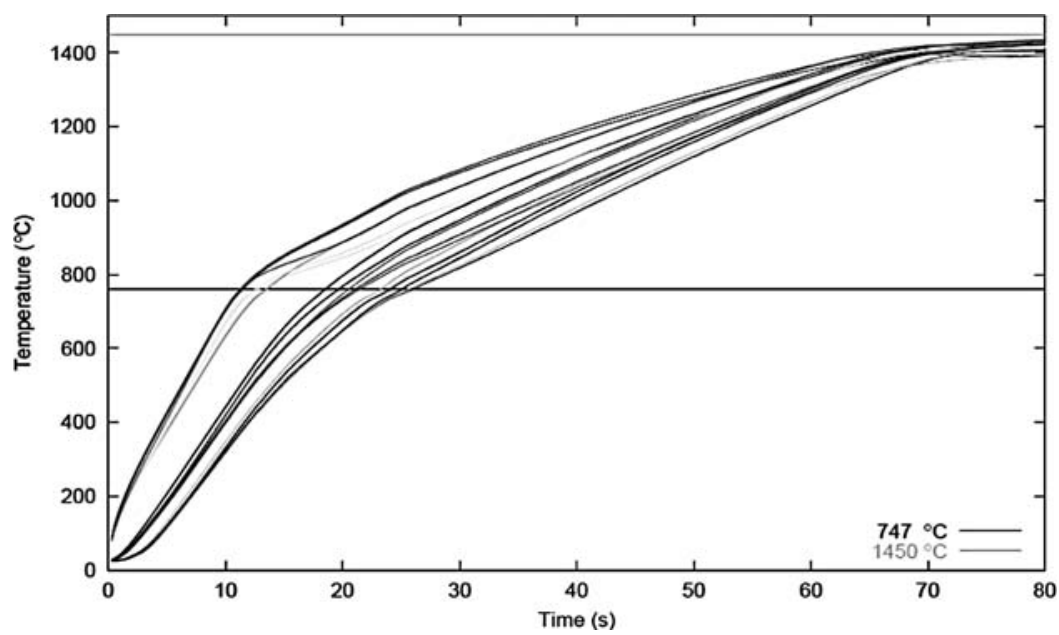

Fig. 41. Temperature distribution in different points of the billet

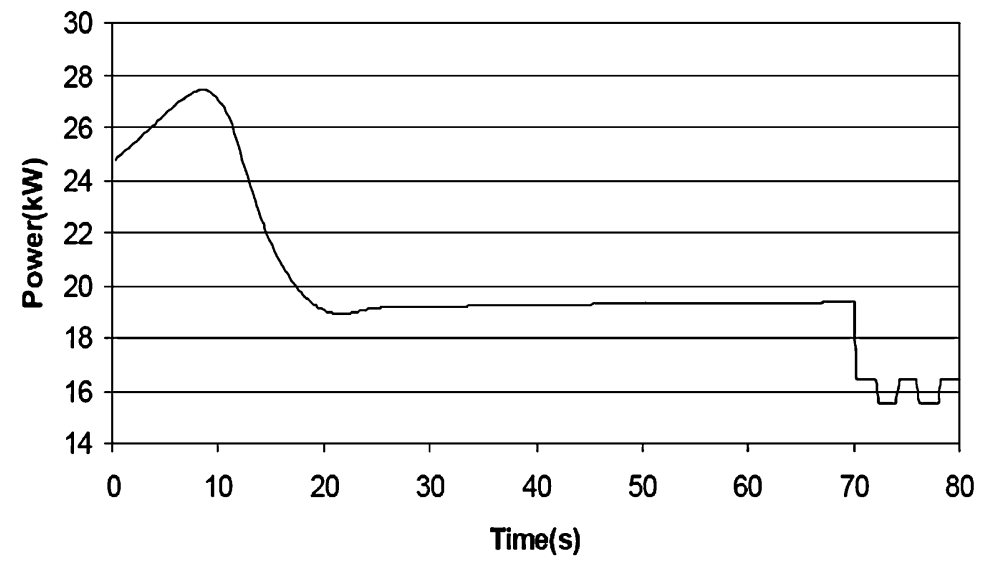

Fig. 42. Simulated heating power in the case of the SKL Flange

equipment that allow the measurement of this parameter. We will later have an electrical resistivity apparatus and the correct parameter will then be introduced in the simulations. Figure 45 gives a comparison between the simulated and measured temperatures in the cold (top) and the hot (centre) part of the billet. The comparison between the simulated and measured temperatures is also shown.

A nearly good agreement is to be stressed. The difference between the results at medium temperatures is due to the energy losses either by radiation or by convection, which is very difficult to handle on one hand and the fact 


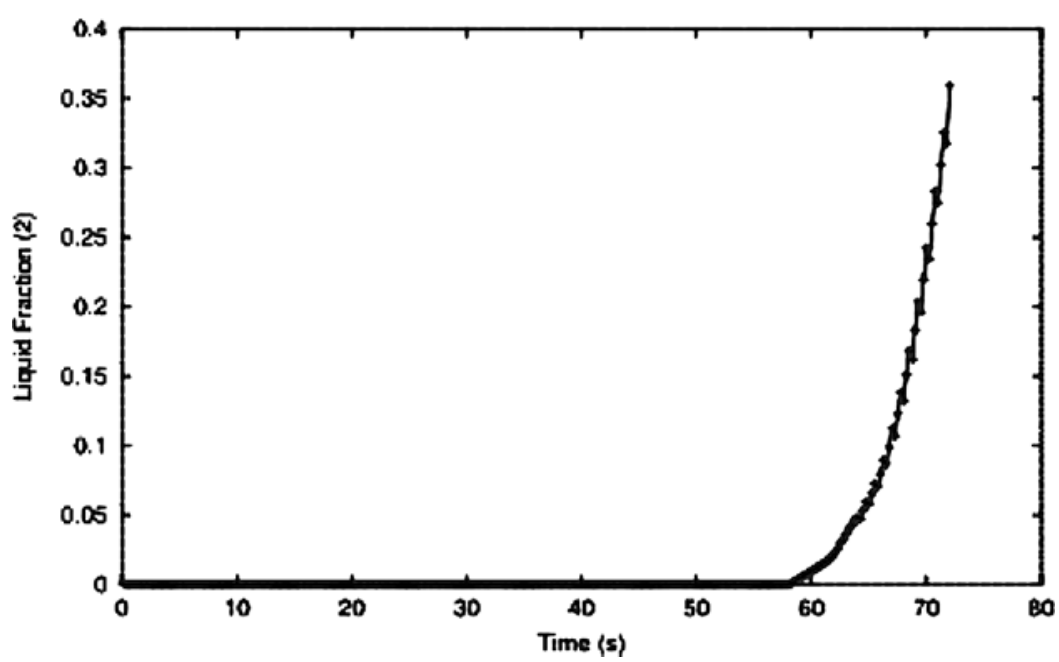

Fig. 43. Simulated average liquid fraction distribution in the billet

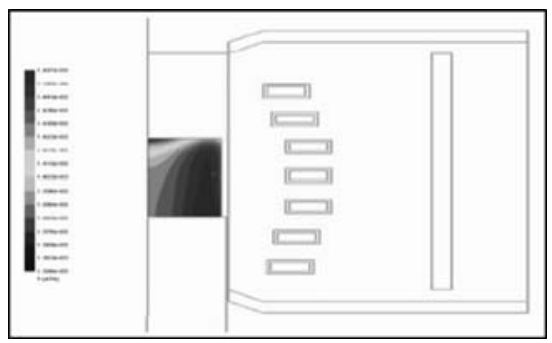

Fig. 44. Used geometry for the validation tests and the temperature distribution in the billet

that experimental measurements by thermocouples are not so easy in the other hand.

Last but not least Fig. 46 represents the used heating power. Note that we have shown in this report only relevant results. Some more validations will be realized in order to improve more and more our simulation model.

For the automation of the described process a control system was developed which still needs thermo sensors for the determination of the billet temperature. For the next development step of this system it is planned to dispense these sensors because with a focus on industrial production of thixoforming parts they are not workable. Instead of direct measuring, the billet temperature will be calculated from easy acquirable parameters such as heating power, current etc. by applying a suitable mathematical model. The development of such a model is currently subject of simulation and research work. 


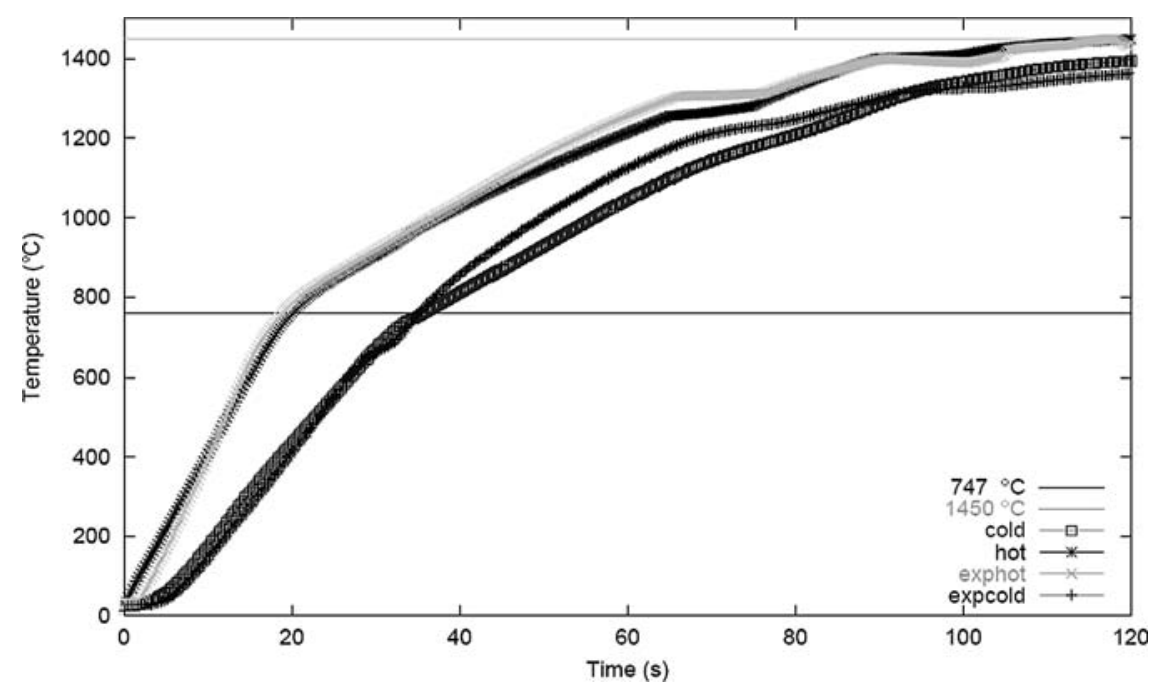

Fig. 45. Temperature validation in the centre and the top of the billet

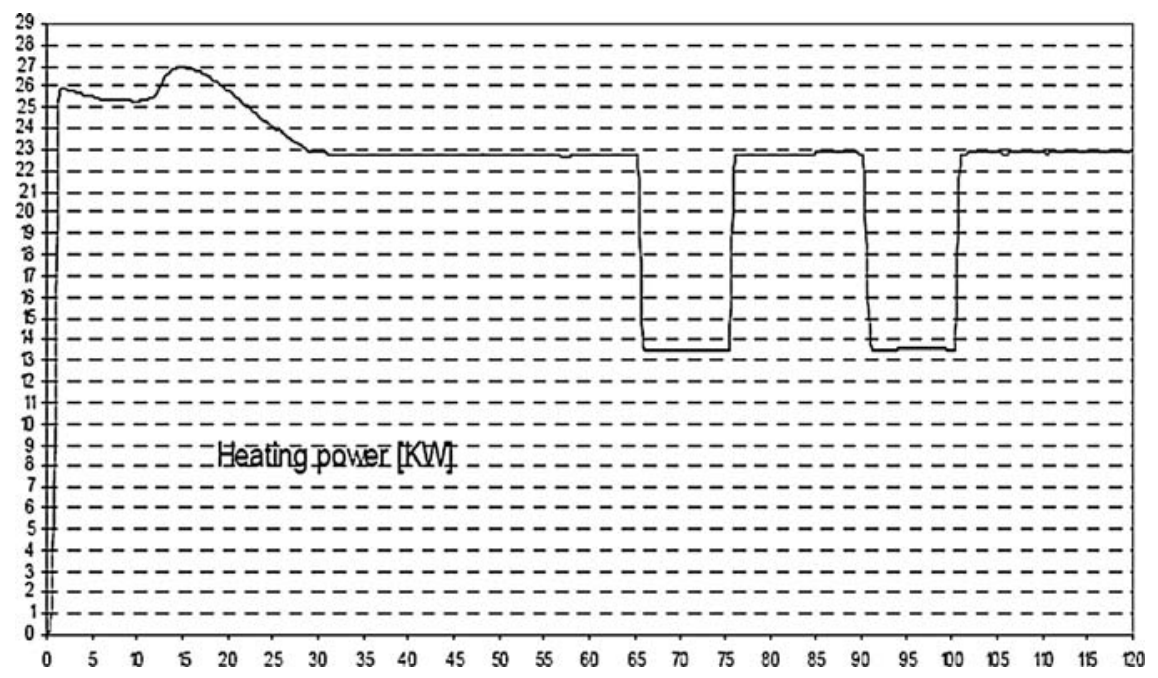

Fig. 46. Validation experimental heating power

The inductive heating of the steel billets is today controlled by the adjusted heating cycles. Once an appropriate cycle is determined, it is assumed that always the same amount of material is to be re-heated whereas the duration and the amount of liquid fraction as well as the temperature to be reached are identical. 


\section{Conclusions}

Thixoforming of steels is more and more investigated. The outcome of some important development results has required several tests and experiments either numerical or practical.

The DSC measurements and corresponding liquid fraction versus temperature were used to study different alloys. For non alloyed steels, C38 Asco modif 2 shows better behaviour as regarding $T_{0}, T_{1},\left(T_{f}-T_{1}\right)$ and $d F / d T\left(T_{1}, T_{f}\right)$ than C38. For low alloyed steels 100 Cr6, 100 Cr6 Asco modif 1 and 50 Mn6 Asco modif 1 show good behaviour. They could be chosen as candidates for thixoforming.

Thermophysical properties characterisations are obtained on C38 Asco modif 2 ( $\alpha, C T E$, density, $C_{p}$, thermal diffusivity and thermal conductivity). As regards to thermal conductivity, a dramatic diminution is observed during melting. These properties were then used for the simulation of heating phase. Thanks to the simulations, a lot of money and effort were saved at different levels. Several improvements are still to be made and the thixoforming of steels has not yet revealed all its secrets.

\section{References}

Atkinson H.V., Kapranos P., Kirkwood D.H., "Alloy Development for Thixoforming", International Conference on Semi-Solid Processing of Alloys and Composites, Torino, September 27-29 (2000), 445-446; Ed. G.L. Chiarmetta, M. Rosso, Edimet, Italy.

Cape J.A., Lehman G.W., "Temperature and Finite Pulse-Time Effects in the Flash Method for Measuring Thermal Diffusivity", Journal of Applied Physics, 37 (1963), 1909.

Dular P., Rassili A., Meys B., Henrotte F., Hedia H., Genon A., and Legros W., "A software environment for the treatment of discrete coupled problems and its application to magneto-thermal coupling", the $4^{\text {th }}$ International Workshop on "Electric and Magnetic Fields, from numerical models to industrial applications" Marseilles 12-15 May 1998 pp. 547-552; Ed. AIM Association des Ingénieurs Diplômés de l'Institut d'Electricité de Montéfiore (Ulg).

Kazakov A.A., "Alloy Compositions for Semisolid Forming", Advanced Materials \& Processes, (2000), 31-34.

Lecomte-Beckers J., Rassili A., Carton M., and Robelet M., "Characterisation of Thermophysical Properties of Semi-Solid Steels for Thixoforming", Proceedings of the $8^{\text {th }}$ International Conference on Semi-Solid Processing of Alloys and Composites, Cyprus, September 21-23 (2004); Ed. Worcester Polytechnic Institute, $M A$.

Lecomte-Beckers J., Rassili A., Carton M., and Robelet M., "Study of Liquid Fraction Evolution of Semi-Solid Steels for Thixoforming", Proceedings of the $8^{\text {th }}$ ESAFORM Conference on material forming, Cluj-Napoca, Romania, April 27-29 (2005), 1087;Ed. The Publishing House of the Romanian Academy. 
Meuser H., Bleck W., "Determination of Parameters of Steel Alloys in the Semi-Solid State", Proceedings of the $7^{\text {th }}$ International Conference on Semi-Solid Processing of Alloys and Composites, Tsukuba, Japan (2002), 349; Ed. Yasukata Tsutsui, Manabu Kiuchi, Kiyoshi Ichikawa.

Rassili A., Geuzaine Ch., Legros W., Bobadilla M., Cucatto A., Robelet M., Abdelfattah S., Dohmann J., and Hornhardt Ch., "Simulation of adequate Inductive Heating Parameters and The Magneto-Thermal coupling involved in the SSM Processing of Steels", Proceedings of the $6^{\text {th }}$ International Conference on Semi-Solid Processing of Alloys and Composites, Torino, September 27-29 (2000); Ed. G.L. Chiarmetta, M. Rosso, Edimet, Italy 